\title{
Dimensional Accuracy of Multiple Pour Cast from Different Elastomer Impression Techniques
}

\author{
${ }^{1}$ Satheesh B Haralur, ${ }^{2}$ Majed S Toman, ${ }^{3}$ Abdullah A Al-Shahrani, ${ }^{4}$ Abdullah A Al-Qarni
}

\begin{abstract}
Context: The elastomeric impression material is the most widely used impression material in contemporary dental practice; their accuracy is critical for the outcome of indirect restorations. The accurate duplicate cast obtained from single impression reduces the professional clinical time, patient inconvenience, and extra material cost.
\end{abstract}

Aim: To compare the accuracy of the cast obtained from various impression methods utilizing elastomer impression materials.

Materials and methods: The stainless steel working cast model assembly consisting of two abutments and one pontic area was fabricated. Two sets of six each custom aluminum trays were fabricated, with $5 \mathrm{~mm}$ spacer and $2 \mathrm{~mm}$ space. The impression methods evaluated in the study were additional silicone putty reline (two step), heavy-light body (one step), monophase (one step), and polyether (one step). Type IV gypsum casts were poured at intervals of $1,12,24$, and 48 hours. The resultant cast was measured with a traveling microscope for comparative dimensional accuracy. The data obtained were subjected to analysis of variance test at significance level $<0.05$.

Results: The die obtained from putty reline two-step impression techniques had the percentage of variation for the height -0.36 to $-0.97 \%$ with 0.40 to $0.90 \%$ increase in diameter. One-step heavy-light body impression dies recorded the increased width by 0.50 to $0.80 \%$ and height reduced by -0.73 to $-1.21 \%$. The resultant dies from additional silicone monophase impressions had a percentage of variation for width $1.20 \%$ and height by $-1.34 \%$. The similar value for width and height for polyether was $-1.46 \%$ and $-1.30 \%$ respectively.

Conclusion: Putty reline technique dies had better dimensional accuracy after repeated pour followed by dies from heavy-light body additional silicone impression.

Key message: The multiple pour cast from putty reline elastomeric impressions is clinically acceptable, while cast from polyether was smaller in dimension.

Keywords: Elastomer impression techniques, Impression accuracy, Working cast and dies.

How to cite this article: Haralur SB, Toman MS, Al-Shahrani AA, Al-Qarni AA. Dimensional Accuracy of Multiple Pour Cast from

\footnotetext{
${ }^{1}$ Associate Professor, ${ }^{2}$ Demonstrator, ${ }^{3}$ Postgraduate Student ${ }^{4}$ Intern

${ }^{1-4}$ Department of Prosthodontics, King Khalid University, College of Dentistry, Abha, Kingdom of Saudi Arabia

Corresponding Author: Satheesh B Haralur, Associate Professor, Department of Prosthodontics, King Khalid University College of Dentistry, Abha, Kingdom of Saudi Arabia, Phone: +966555835386, e-mail: hb_satheesh@yahoo.com
}

Different Elastomer Impression Techniques. Int J Prosthodont Restor Dent 2016;6(3):51-56.

Source of support: Nil

Conflict of interest: None

\section{INTRODUCTION}

Indirect restorations constitute a large part of restorative and prosthetic treatment plan. ${ }^{1}$ The accurate and dimensionally stable impressions are indispensable for the fabrication of indirect restoration. An impression is a record, a facsimile of the oral tissues recorded at an unstrained or various positions of displacement. ${ }^{2}$ The excellent tooth preparation is of little value unless its details are accurately transferred to the laboratory. The precise dental cast facilitates the technician to fabricate the ideal restoration. The previous studies observed that the inaccurate and poorly adapted restoration led to compromised esthetics with the biological failure of fixed partial denture.

Over the years, dental materials have been developed to improve their dimensional stability, reproducibility, and handling. The impression methods have evolved to complement the recent material advancement to improve the impression accuracy. The selection of the impression methods is entirely at the discretion of the dentist. It is mainly influenced by the clinical conditions and variations. The elastomeric impression materials are most widely used in restorative dentistry due to multiple advantages ${ }^{3}$ like good reproducibility, elastic recovery, and dimensional stability. The majority of impression techniques comprise different viscosity impression materials. The high-viscosity material is used as a preliminary impression; low-viscosity materials are utilized to record the finer details of preparation. Both single-stage and two-stage impressions are known to provide accurate impressions. ${ }^{4-6}$

The accuracy of an impression with repeated pour is of great advantage for the clinician and laboratory technicians. It reduces the professional clinical time, patient inconvenience, and extra material cost. The change of interabutment during cast sectioning and loss of gingival reference during die ditching necessitate the additional intact duplicate cast for verification of finished restoration. ${ }^{7}$

The dimensional accuracy of the cast from repeated pour is influenced by the extent of elastic recoil from 
distortion during cast retrieval and continued polymerization shrinkage. These factors are greatly affected by the thickness/nature of impression material and stress induced during impression procedures. Hence, it is important to understand the role of different impression methods on the dimensional accuracy of the resultant dies, especially on the multiple pours. The objective of the study was to compare the dimensional accuracy of the cast obtained from various impression methods on the multiple pours of a single impression at various time intervals. The impression methods evaluated in the study were two-stage putty relined with light additional polyvinyl siloxane, single-stage heavy-light body additional silicone, monophase single stage, and polyether single step.

\section{MATERIALS AND METHODS}

Institutional ethical committee approval was obtained for the study research proposal. The stainless steel working cast model assembly consisting of two abutments and one pontic area was fabricated (Fig. 1). The stainless steel abutments were made to simulate the full veneer crown preparation with uniform $2 \mathrm{~mm}$ shoulder finish line and $6^{\circ}$ taper. The first abutment was $8.2 \mathrm{~mm}$ in height, $9.9 \mathrm{~mm}$ diameter at the occlusal surface. The measurements at the similar location for the second abutment were $7.6 \mathrm{~mm}$ height and $7.04 \mathrm{~mm}$ diameter. The interabutment distance was $14.93 \mathrm{~mm}$. The occlusal surface of the abutment was flat with reference to cross-groove for precise measurement. Two set of perforated, rectangular custom aluminum trays were fabricated for making an impression (Fig. 2).

The first set of six impression trays was used for putty wash impression technique; they possessed uniform spacer width of $5 \mathrm{~mm}$. Another set of impression had $2 \mathrm{~mm}$ uniform spacer area for a heavy body-light body one-step impression method. The impression tray stopper on working cast model base maintained a uniform space

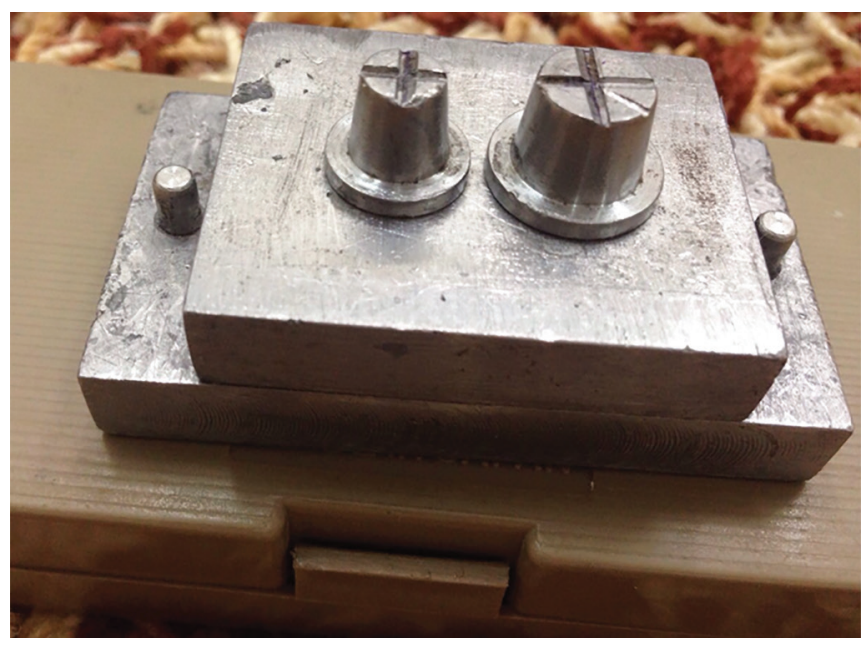

Fig. 1: Stainless steel master cast used in the study for the impression. The corresponding pin on the cast and groove in the impression trays was helpful in accurate position and immobilization of trays during impression procedure.

The impression methods compared in the study were the two-step putty reline technique, one-step heavy-light body, and one-step monophase polyvinyl siloxane material. The study also included the one-step monophase polyether impression.

The impression procedures were conducted at controlled room temperature $\left(25 \pm 10^{\circ} \mathrm{C}\right)$ following manufacturer's instruction. The silicone/polyether tray adhesive applied over the tray allowed to dry for 10 minutes prior to the impression procedure. Weight in precision scale established the base and catalyst proportion; $20 \mathrm{gm}$ of each constituent was used in the study. One millimeter uniform spacer thickness was obtained by adapting the vacuum resin sheet over the model for two-stage putty wash technique. In the first stage, the mixed putty was loaded in the tray and allowed to set over the cast for 4 minutes. The second stage involved the removal of the spacer and relining the preliminary putty impression with light body elastomers.

The single-stage heavy-light body impression was accomplished by simultaneous loading of the heavy consistency material in the tray, and light viscosity material was spread over the stainless steel die. The impression tray was placed over the cast, and both the layers of the impression materials were allowed to set for 5 minutes. The single-stage impression from polyvinyl siloxane mono-phase and polyether single consistency impression was done in the similar procedure except the overlying light-body impression materia (Fig. 3).

After impression procedure, all polyvinyl siloxane impressions were rinsed in water and disinfected with sodium hypochlorite (1:10) immersion for 3 minutes.

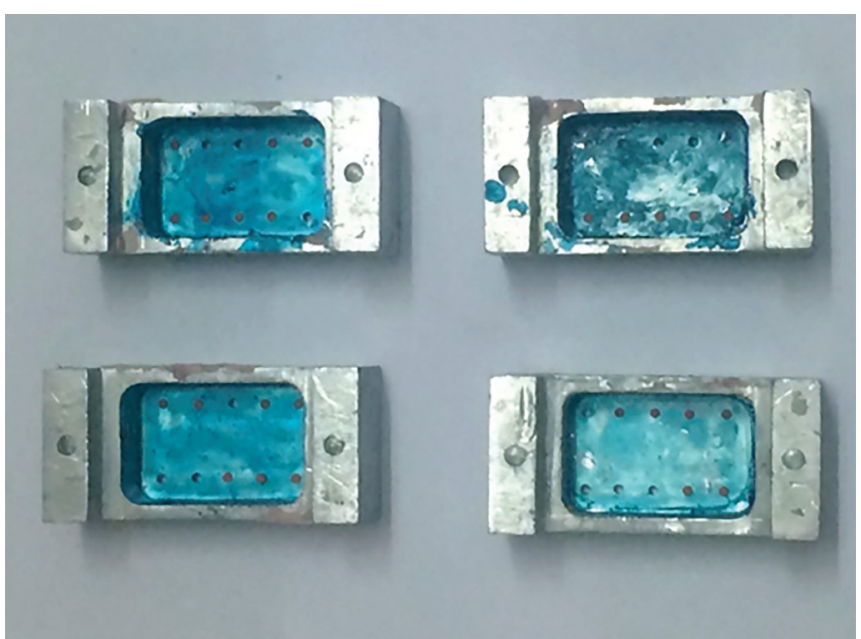

Fig. 2: Aluminum impression trays used in the study 


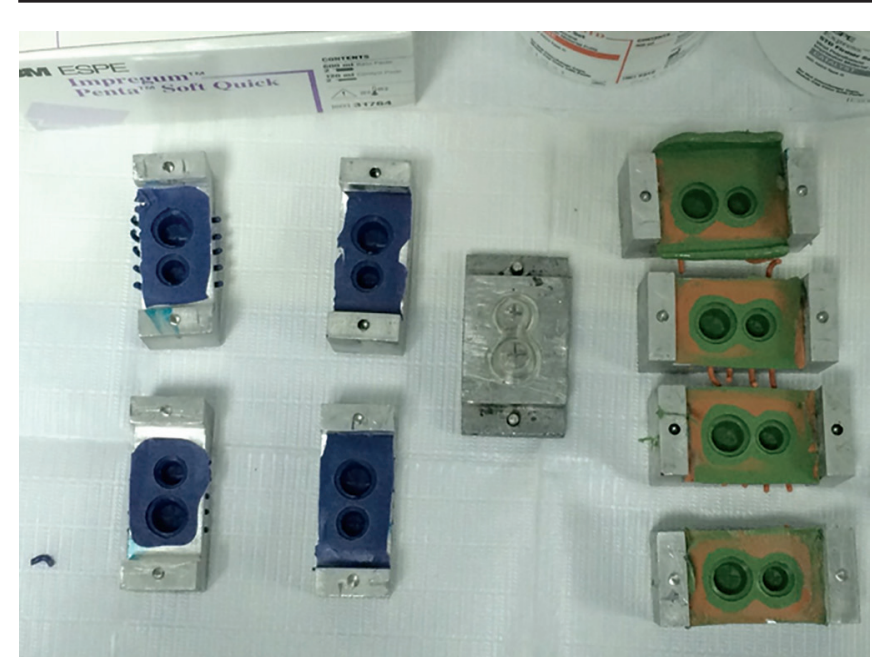

Fig. 3: Polyether and putty reline impression made in custom trays

The polyether impressions were disinfected with sodium hypochlorite spray.

All the impressions were stored at $25 \pm 10^{\circ} \mathrm{C}$ for 1 hour for elastic recovery and hydrogen release of vinyl polysiloxane. Following the manufacturer's instruction, $30 \mathrm{gm}$ of preweighed type IV gypsum was mixed with $6 \mathrm{~mL}$ of distilled water to obtain 0.20 water-powder ratio. The vacuum mixer was utilized for gypsum mixing, and it was poured into the impression under mechanical vibration (Fig. 4). The stainless steel retentive struts were attached to the cast base for easy removal of the set cast. The set gypsum cast was removed from the cast after 1 hour with due care, to avoid impression damage.

The $2 \mathrm{nd}$, 3rd, and 4 th dental cast were obtained following a similar procedure after 8 hours, 24 hours, and 3 days interval from the same impression. All the measurements were performed after complete drying of gypsum cast. The measurement of set gypsum cast for linear dimensional change at the reference points was accomplished by a traveling microscope with $0.01 \mu \mathrm{m}$ accuracy. The obtained data were subjected to analysis of variance (ANOVA) test at significance level $<0.05$. The percentage of variation of stone dies from the master cast was calculated by the following formula:

$\begin{aligned} & \text { Percentage } \\ & \text { of deviation }\end{aligned}=\frac{\text { mean stone dimension }- \text { mean master dimension }}{\text { mean master dimension }} \times 100$

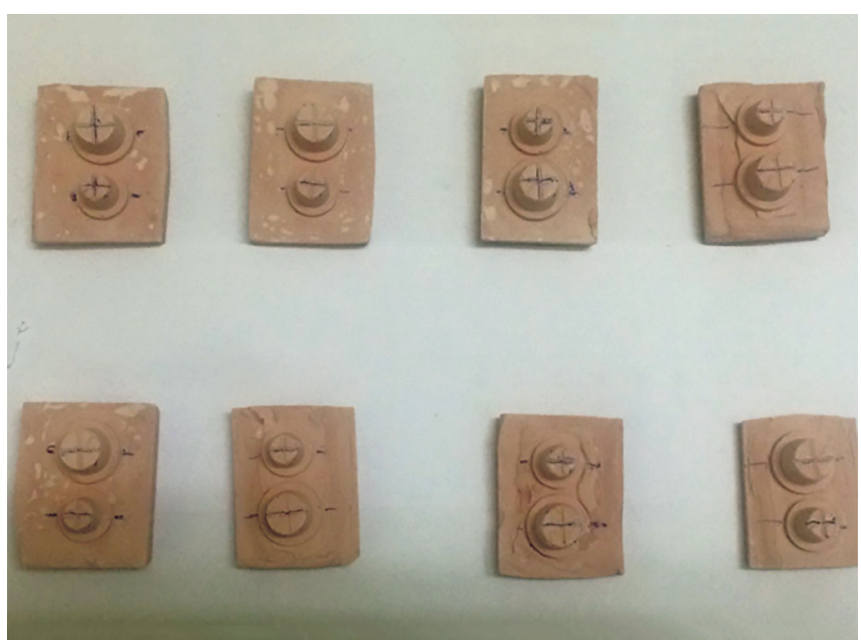

Fig. 4: Stone dies obtained from impression

\section{RESULTS}

The present study evaluated the accurate reproducibility of dental die from repeated impression at different time intervals. Elastomers are commonly used for the impression making in contemporary dentistry. Hence, they were chosen for the evaluation in the study. The impressions were poured at 1, 12, 24, and 48-hour interval.

Table 1 lists the mean values, standard deviation, and percent deviation of the stone die obtained from putty reline two-step impression technique. The dies obtained from this technique were shorter in height and wider in diameter. There was a progressive reduction of the percentage of variation for the height on repeated pour from -0.36 to $-0.97 \%$. The interabutment distance was increased up to $0.40 \%$ after repeated pour. The upper diameter of the die was increased by 0.40 to $0.90 \%$, the lower diameter showed increase in diameter by 0.04 to $0.12 \%$. One-way ANOVA showed all the significant variation among all the measurements except the upper diameter of abutment with a p-value of 0.424 .

Table 2 shows the mean measurement values with the percentage of deviation for die in a heavy-light body one-step impression method. The resultant dies were also shorter and wider in diameter. The abutment height was reduced in the range of -0.73 to $-1.21 \%$, while the upper diameter of the abutment was increased by 0.50 to $0.80 \%$.

Table 1: The mean measurement values of stone dies, standard errors, and percentage of errors from master cast from putty reline impression technique

\begin{tabular}{|c|c|c|c|c|c|c|c|c|c|c|c|c|c|}
\hline \multirow[b]{2}{*}{ Measurement } & \multicolumn{3}{|c|}{$\begin{array}{l}\text { First pour } \\
\text { (1 hour) }\end{array}$} & \multicolumn{3}{|c|}{$\begin{array}{l}\text { Second pour } \\
\text { (12 hours) }\end{array}$} & \multicolumn{3}{|c|}{$\begin{array}{l}\text { Third pour } \\
\text { (24 hours) }\end{array}$} & \multicolumn{3}{|c|}{$\begin{array}{c}\text { Fourth pour } \\
\text { (48 hours) }\end{array}$} & \multirow[b]{2}{*}{$p$-value } \\
\hline & Mean & $S D$ & $\%$ & Mean & $S D$ & $\%$ & Mean & $S D$ & $\%$ & Mean & $S D$ & $\%$ & \\
\hline Upper diameter of abutment & 10.03 & 0.13 & 0.40 & 10.04 & 0.05 & 0.50 & 10.08 & 0.02 & 0.90 & 10.06 & 0.01 & 0.70 & 0.424 \\
\hline Lower diameter of abutment & 15.65 & 0.03 & 0.12 & 15.65 & 0.04 & 0.12 & 15.71 & 0.05 & 0.05 & 15.66 & 0.05 & 0.04 & 0.000 \\
\hline Interabutment distance & 14.96 & 0.03 & 0.20 & 14.98 & 0.14 & 0.27 & 15.02 & 0.18 & 0.0 & 14.99 & 0.05 & 0.40 & 0.000 \\
\hline Height abutment & 8.17 & 0.04 & -0.36 & 8.15 & 0.03 & -0.60 & 8.12 & 0.03 & -0.97 & 8.16 & 0.03 & -0.48 & 0.000 \\
\hline
\end{tabular}

SD: Standard deviation 
Table 2: The mean measurement values of stone dies, standard errors, and percentage of errors from master cast from heavy-light body single mix impression technique

\begin{tabular}{|c|c|c|c|c|c|c|c|c|c|c|c|c|c|}
\hline \multirow[b]{2}{*}{ Measurement } & \multicolumn{3}{|c|}{$\begin{array}{c}\text { First pour } \\
\text { (1 hour) }\end{array}$} & \multicolumn{3}{|c|}{$\begin{array}{c}\text { Second pour } \\
\text { (12 hours) }\end{array}$} & \multicolumn{3}{|c|}{$\begin{array}{l}\text { Third pour } \\
\text { ( } 24 \text { hours) }\end{array}$} & \multicolumn{3}{|c|}{$\begin{array}{c}\text { Fourth pour } \\
\text { (48 hours) }\end{array}$} & \multirow[b]{2}{*}{$p$-value } \\
\hline & mean & $S D$ & $\%$ & Mean & $S D$ & $\%$ & Mean & $S D$ & $\%$ & Mean & $S D$ & $\%$ & \\
\hline Upper diameter of abutment & 10.04 & 0.04 & 0.50 & 10.05 & 0.05 & 0.60 & 10.08 & 0.06 & 0.90 & 10.07 & 0.03 & 0.80 & 0.647 \\
\hline Lower diameter of abutment & 15.66 & 0.03 & 0.19 & 15.65 & 0.14 & 0.12 & 15.74 & 0.16 & 0.03 & 15.74 & 0.13 & 0.02 & 0.000 \\
\hline Interabutment distance & 14.98 & 0.04 & 0.04 & 15.01 & 0.04 & 0.20 & 15.04 & 0.05 & 0.53 & 14.99 & 0.03 & 0.40 & 0.008 \\
\hline Height abutment & 8.14 & 0.04 & -0.73 & 8.14 & 0.06 & -0.73 & 8.11 & 0.05 & -1.09 & 8.10 & 0.05 & -1.21 & 0.020 \\
\hline
\end{tabular}

SD: Standard deviation

Table 3: The mean measurement values of stone dies, standard errors, and percentage of errors from master cast from monophase impression technique

\begin{tabular}{|c|c|c|c|c|c|c|c|c|c|c|c|c|c|}
\hline \multirow[b]{2}{*}{ Measurement } & \multicolumn{3}{|c|}{$\begin{array}{c}\text { First pour } \\
\text { (1 hour) }\end{array}$} & \multicolumn{3}{|c|}{$\begin{array}{l}\text { Second pour } \\
\text { (12 hours) }\end{array}$} & \multicolumn{3}{|c|}{$\begin{array}{l}\text { Third pour } \\
\text { (24 hours) }\end{array}$} & \multicolumn{3}{|c|}{$\begin{array}{l}\text { Fourth pour } \\
\text { (48 hours) }\end{array}$} & \multirow[b]{2}{*}{$p$-value } \\
\hline & Mean & $S D$ & $\%$ & Mean & $S D$ & $\%$ & Mean & $S D$ & $\%$ & Mean & $S D$ & $\%$ & \\
\hline Upper diameter of abutment & 10.06 & 0.08 & 0.70 & 10.09 & 0.07 & 1.00 & 10.13 & 0.07 & 1.20 & 10.10 & 0.05 & -0.70 & 0.000 \\
\hline Lower diameter of abutment & 15.71 & 0.08 & 0.51 & 15.76 & 0.07 & 0.63 & 15.80 & 0.07 & 0.83 & 15.78 & 0.07 & 0.70 & 0.002 \\
\hline Interabutment distance & 15.12 & 0.05 & 1.27 & 15.15 & 0.06 & 1.47 & 15.15 & 0.05 & 1.47 & 15.13 & 0.03 & 0.73 & 0.074 \\
\hline Height abutment & 8.16 & 0.17 & -0.48 & 8.14 & 0.07 & -0.73 & 8.09 & 0.08 & -1.34 & 8.12 & 0.11 & -0.97 & 0.124 \\
\hline
\end{tabular}

SD: Standard deviation

Table 4: The mean measurement values of stone dies, standard errors, and percentage of errors from master cast from polyether impression technique

\begin{tabular}{|c|c|c|c|c|c|c|c|c|c|c|c|c|c|}
\hline \multirow[b]{2}{*}{ Measurement } & \multicolumn{3}{|c|}{$\begin{array}{c}\text { First pour } \\
\text { (1 hour) }\end{array}$} & \multicolumn{3}{|c|}{$\begin{array}{l}\text { Second pour } \\
\text { (12 hours) }\end{array}$} & \multicolumn{3}{|c|}{$\begin{array}{l}\text { Third pour } \\
\text { (24 hours) }\end{array}$} & \multicolumn{3}{|c|}{$\begin{array}{c}\text { Fourth pour } \\
\text { (48 hours) }\end{array}$} & \multirow[b]{2}{*}{$p$-value } \\
\hline & Mean & $S D$ & $\%$ & Mean & $S D$ & $\%$ & Mean & $S D$ & $\%$ & Mean & $S D$ & $\%$ & \\
\hline Upper diameter of abutment & 9.94 & 0.08 & -0.50 & 9.86 & 0.77 & -1.30 & 9.88 & 0.06 & -1.10 & 9.89 & 0.05 & -1.00 & 0.012 \\
\hline Lower diameter of abutment & 15.56 & 0.08 & -0.44 & 15.53 & 0.07 & -0.63 & 15.52 & 0.07 & -0.70 & 15.55 & 0.05 & -0.51 & 0.031 \\
\hline Interabutment distance & 14.86 & 0.10 & -0.46 & 14.79 & 0.21 & -0.93 & 14.76 & 0.03 & -1.13 & 14.82 & 0.03 & -0.73 & 0.181 \\
\hline Height abutment & 8.17 & 0.20 & -0.36 & 8.08 & 0.18 & -1.46 & 8.11 & 0.15 & -1.09 & 8.15 & 0.10 & -0.60 & 0.003 \\
\hline
\end{tabular}

SD: Standard deviation

The interabutment distance between the abutments had $0.53 \%$ variation after pour at 24 hours. The percentage of variation for dies was progressively increased over repeated pouring of the same impression. The p-value was statistically significant for all measurements except upper diameter of abutment with a value of 0.647 .

Table 3 indicates the stone die measurement obtained from monophase impression along with the percentage of variation from the master die. The percentage of variation was large in this group in comparison with other methods. The mean percentage of variation for interabutment width was $1.47 \%$, and the abutment height variation was up to $-1.34 \%$. The abutment at upper diameter variation was $1.20 \%$; lower location was $0.83 \%$. The dimensional accuracy of dies was significantly varied over repeated pour at abutment of upper and lower diameter with a p-value of 0.00 and 0.002 respectively.

Table 4 shows the mean measurement values and percentage of variation for the polyether impression group. This group showed the highest variation in dimension after repeated pour. The resultant dies after repeated pour were both shorter in diameter and height. The change for dies varied from -0.36 to -1.46 in height and -0.50 to -1.30 for upper diameter. The interabutment distance was also decreased in the range of -0.46 to $-1.13 \%$.

\section{DISCUSSION}

Accurate impression is critical for the fabrication of precise indirect cast restorations. The favorable prognosis of cast restorations is mainly dependent on the well-adapted margins. ${ }^{8}$ The multiple pours of dental impression are required in various situations ranging from inadvertent damage to verification of contact and emergence profile on intact cast. ${ }^{9}$ The impression materials and methods capable of providing dimensionally accurate die on repeated pour is to the great advantage of clinicians and laboratory technicians. The study explored the commonly used impression method in their ability to produce an accurate die after multiple pours. The accuracy of impression material is attributed to multiple factors including elastic recovery, the direction of setting contraction, continuous polymerization, and evaporation of volatile contents. 
The additional silicone impression material is most commonly used in dentistry due to its better accuracy, ${ }^{10}$ easy manipulation, and patient acceptance. Researchers are of the opinion that the precision of the impression can be controlled by the impression method than the material itself. The study reinforces the opinion of the researchers that the accuracy of dies varied significantly between different impression methods. ${ }^{10}$ Chee et $\mathrm{al}^{3}$ on comparing between double-mix and single-mix putty reline technique concluded that the double-mix twostage impression provided more accurate cast. The main disadvantage of single-mix technique reported by the researchers was the failure to record the finer details. Few researchers, such as Hung et $\mathrm{al}^{11}$ and Idris et $\mathrm{al}^{12}$ reported the insignificant difference between the double-mix and single-mix technique in accuracy. The study evaluated the two-step putty reline with light body additional silicone impression method. According to the recommendation of earlier researchers, the wash bulk of $1 \mathrm{~mm}$ was utilized in the study for improved dimensional accuracy of dies. ${ }^{13}$

The study showed that the dies obtained of one-step heavy-light body impression and monophase impression were relatively wider in diameter than the master dies in comparison with two-stage putty reline technique. The wider dies on multiple pours due to polymerization shrink toward the wall of the impression tray. The polymerization shrinkage was least in putty-relined technique due to the low matrix and filler ratio. ${ }^{14}$ Researchers recommend the double-mix single-step impression to eliminate the inaccuracies in the cast due to deformation and elastic recoil of first phase material. ${ }^{15}$ The reseating and removal for the light body relining process led to the deformation of already set high-viscosity putty material. Hence, resultant dies from putty reline technique showed a slight variation in dimension. The results of the study indicate that the extended time allowed the recovery of impression from the strain and improved the accuracy of the dies. The results of the study indicate that the single-step heavy-light body single-mix impression technique showed the percentage of variation in the width ranging from 0.04 to 0.90 . The subsequent dies obtained from multiple pours were significantly inaccurate. The second and the third pour exhibited the percentage of variation of 0.05 and $0.06 \%$ respectively. The dimensional change was slightly higher than putty reline impression techniques. The compromised elastic recovery of heavy body impression material is due to the less proportion of filler particle in comparison to the putty material. ${ }^{16}$ The inability in maintaining the uniform thickness of light body material also led to larger dimensional changes. ${ }^{17}$ The dies obtained from multiple pours had -0.36 to $-0.97 \%$ of variation. The results of the study are in agreement with those of Stackhouse. ${ }^{18}$ The shorter dies are due to contraction of vertical dimension toward the occlusal preparation with impression attached to the tray.

Larger sections of clinicians prefer the monophase impression material due to its quick and easy impression procedure. The procedure is accomplished in one step utilizing single consistency impression material. The results of the study indicate that the upper diameter of the dies had increased the percentage of variation in the range of 0.70 to 1.20 . The die produced after repeated impression pour was shorter than the master cast up to $1.34 \%$. The percentage of variations was significantly higher in comparison to putty reline and single-step heavy-light body impression technique. The results are in compliance with the observation of Millar et al, ${ }^{19}$ who reported the poor dimensional accuracy and high surface defects in monophase impression material because of its relatively high viscosity and reduced flow. Johnson et $\mathrm{al}^{9}$ reported the larger die diameter due to the contraction of impression material toward the walls of impression tray.

Polyether impression materials continue to be preferred by clinicians due to its hydrophilic nature, improved flow, and easy manipulation. Rigidity of the polyether continues to be its main disadvantage, leading to difficulty in removing the impression. The dies prepared with polyether impression material were small both in diameter and in height. The dimensional accuracy of the dies on multiple pours was significantly poor. The results could be due to the inability of polyether impression material in its elastic recovery. It is known for good short-term dimensional stability. The water imbibition from gypsum during setting reaction also leads to the dimensional inaccuracy of dies.

\section{CONCLUSION}

Within the limitations of the study, following conclusions were drawn. The putty reline technique (two step) and heavy-light body additional silicone (one step) resulted in the lowest percentage of variation from the master model. Monophase impression technique produced the least dimensional accuracy. The shrinkage of impression material led to larger diameter and shorter dies. The polyether impression showed the highest distortion over repeated pour, due to lesser ability to recover. All the impression techniques showed statistically significant changes in dimension over the repeated impression pour.

\section{REFERENCES}

1. Christensen GJ. Indirect restoration use: a changing paradigm. J Am Dent Assoc 2012 Apr;143(4):398-400.

2. Devan MM. Basic principles in impression making. J Prosthet Dent 2005 Jun;93(6):503-508.

3. Chee WW, Donovan TE. Polyvinyl siloxane impression materials: a review of properties and techniques. J Prosthet Dent 1992 Nov;68(5):728-732 
4. Nissan J, Laufer BZ, Brosh T, Assif D. Accuracy of three polyvinyl siloxane putty-wash impression techniques. J Prosthet Dent 2000 Feb;83(2):161-165.

5. Nissan J, Gross M, Shifman A, Assif D. Effect of wash bulk on the accuracy of polyvinyl siloxane putty-wash impressions. J Oral Rehabil 2002 Apr;29(4):357-361.

6. Luthardt RG, Walter MH, Quaas S, Koch R, Rudolph H. Comparison of the three-dimensional correctness of impression techniques randomized controlled trial. Quintessence Int 2010 Nov-Dec;41(10):845-853.

7. Roulet JF. Marginal integrity: clinical significance. J Dent 1994;22 (Suppl 1):S9-S12.

8. Johnson GH, Craig RG. Accuracy of four types of rubber impression materials compared with time of pour and repeat pour of models. J Prosthet Dent 1985 Apr;53(4):484-490.

9. Gonçalves FS, Popoff DA, Castro CD, Silva GC, Magalhães CS, Moreira AN. Dimensional stability of elastomeric impression materials: a critical review of the literature. Eur J Prosthodont Restor Dent 2011 Dec;19(4):163-166.

10. Caputi S, Varvara G. Dimensional accuracy of resultant casts made by a monophase, one-step and two-step, and a novel two-step putty/light-body impression technique: an in vitro study. J Prosthet Dent 2008 Apr;99(4):274-281.

11. Hung SH, Purk JH, Tira DE, Eick JD. Accuracy of one-step versus two-step putty wash addition silicone impression technique. J Prosthet Dent 1992 May;67(5):583-589.
12. Idris B, Houston F, Claffey N. Comparison of the dimensional accuracy of one- and two-step techniques with the use of putty/wash addition silicone impression materials. J Prosthet Dent 1995 Nov;74(5):535-541.

13. Takahashi H, Finger WJ. Effects of the setting stage on the accuracy of double-mix impressions made with additioncuring silicone. J Prosthet Dent 1994 Jul;72(1):78-84.

14. Chen SY, Liang WM, Chen FN. Factors affecting the accuracy of elastomeric impression materials. J Dent 2004 Nov;32(8):603-609.

15. Chee WW, Donovan TE. Fine detail reproduction of very high viscosity poly (vinyl siloxane) impression materials. Int J Prosthodont 1989 Jul-Aug;2(4):368-370.

16. Carlo HL, Fonseca RB, Soares CJ, Correr AB, Correr-Sobrinho L, Sinhoreti MA. Inorganic particle analysis of dental impression elastomers. Braz Dent J 2010;21(6):520-527.

17. de Araujo PA, Jorgensen KD. Effect of material bulk and undercuts on the accuracy of impression materials. J Prosthet Dent 1985 Dec;54(6):791-794.

18. Stackhouse JA Jr. A comparison of accuracy of elastomeric impression material. J Prosthet Dent 1975 Sep;34(3):305-313.

19. Millar BJ, Dunne SM, Robinson PB. In vitro study of the number of surface defects in monophase and two-phase addition silicone impressions. J Prosthet Dent 1998 Jul;80(1): 32-35. 